\title{
Expert Qualifications in Japan: The Role of Higher Education
}

\author{
Kiyoko Saito ${ }^{1}$ \\ ${ }^{1}$ Visiting Associate Professor, Department of Research, National Institution for Academic Degrees and Quality \\ Enhancement, Japan \\ Correspondence: Kiyoko Saito, Visiting Associate Professor, Department of Research, National Institution for \\ Academic Degrees and Quality Enhancement, Japan
}

Received: April 12, 2018

Accepted: June 5, 2018

Online Published: June 12, 2018

doi:10.5430/ijhe.v7n3p183

URL: https://doi.org/10.5430/ijhe.v7n3p183

\begin{abstract}
The goal of this paper was to explore the directions for a Japanese Qualifications Framework (JQF) through the collation of Japanese Government expert viewpoints. This study used a qualitative case study design involving interviews with 15 Japanese government officials. It was found that Japan continues to have problems with academic degrees and licensing framework and system. Many Japanese government experts believed that Japan needed a qualifications framework and system that could function both domestically and internationally, however, Japan has an insufficient qualifications framework and system which has led to weak competitiveness for Japanese experts. To resolve these issues, a Japanese qualifications system needs (1) to have pathways toward higher skill levels from work-based experience to higher education and (2) to broaden pathways allowing for the transfer of Japanese domestic qualifications to international framework qualifications. It is concluded that to build these pathways, National Qualifications Framework is needed as a common language and a basic framework to make the qualifications more transparent and to align domestic and international qualification standards. The Japanese government should enter into a discussion about JQF seriously with stakeholders in education, industry, and government with the aim of improving higher education programs for experts to ensure domestic and international competitiveness.
\end{abstract}

Keywords: academic degrees, expert qualifications, licenses, higher education, labor market, National Qualifications Framework, work experience

\section{Introduction}

Owing to globalization many countries are reforming their qualification systems. Increasing labor movement from company to company, from industry to industry, and from country to country accelerate many countries to reform and form a qualifications system to ensure that workers' skills can be internationally certified. As higher level qualifications can lead to better job outcomes than low level qualifications (Misko, 2012), credential qualifications are becoming increasingly important.

A qualification is defined as the formal and final outcome of an assessment and validation process from a competent body in relation to learning outcomes in a recognized and agreed upon standard for certificate, diploma or other record (European Commission, 2008; Cedefop, 2010, 2013). Qualifications are necessary instruments for governing and regulating the labor markets. By being linked to occupations and expertise, qualifications describe what is needed to know and be able to do carry out a certain activity.

In recent years, developing a good qualifications framework as a gate keeper is seen as an important policy for many countries to control the quality of workers coming in from overseas. Therefore, quality assurance of national qualifications across countries has emerged as a core purpose of introducing qualifications framework (Bateman \& Coles, 2013).

Transparent, coherent, reliable, flexible, and relevant qualifications frameworks have proven to effectively operate as gate keepers. Some countries have well-established National Qualifications Frameworks (NQFs), and others are only in the beginning stages. Because it is necessary to control the quality of workers coming from overseas, and to ensure that domestic workers are more competitive, policy makers are investigating effective NQFs. Therefore, many countries are referencing to regional qualifications such as the European Qualifications Framework (EQF) and the Asian Qualifications Reference Framework (AQRF) as these are transnational meta-frameworks designed to ensure coherence in regional labor and education. 
The Organisation for Economic Co-operation and Development (OECD) has stated that the introduction of qualifications frameworks can facilitate progression pathways in education systems by situating the qualifications at different levels and clarifying how they relate. Transparent progression pathways help to clarify the place of vocational qualifications and facilitate lifelong learning (Organisation for Economic Co-operation and Development, 2010). Governments have argued that higher education participation should be a springboard for individuals to access to satisfying careers and achieve labor mobility (Artess, Tristran \& Mellors-Bourne, 2017), with the implementation of NQF being expected to reflect the global labor market demands and connect academic learning outcomes to the labor market in a range of meaningful ways.

Before 2005, NQF had been set up in three European countries and developed in many countries. However, of all developed countries, only the USA and Japan have not implemented an NQF. Most of these frameworks are now operational and have made an impact on education, training, and employment policies and practices (Cedefop, 2015). Raffe (2013) outlined seven change processes that an NQF is expected to achieve: a common language, stakeholder engagement and coordination, regulation, quality assurance, unitization or modularization, transparency of qualifications, and cultural and pedagogical change. Although NQFs vary (Raffe, 2013; European Training Foundation, 2013), it was observed that the direct regulation of occupations and experts using qualifications seemed to be diminishing, and was being replaced by a weaker and more fluid relationships between qualifications and the labor market (Cedefop, 2013). Cedefop (2015) also found that NQF that were seeking to better coordinate the different national education and training system sub-sectors, to ensure that the NQFs were more transparent were most commonly found in long-settled local systems that have been sustained by a national consensus; that is, changes to the national frameworks or wider systems tended to be adjustments, rather than major overhauls. However, NQF implementation being used as a reform tool to actively improve national education and training system were more typically found in either the newer European Union member or in transitioning and developing countries.

Although many countries are either introducing NQFs or preparing to introduce them, some research has shown that there is limited evidence of successful implementations (Raffe, 2013; Oliver \& Walpole, 2017). Young (2008) found that there were three main NQF implementation problems: political, administrative, and educational; other problems related to NQF objectives have also been highlighted (Allais, 2010; Raffe, 2013). Although one of the important objectives of an NQF is to improve communication between the education and labor markets, little evidence has been presented to confirm the success of this relationship. It has therefore been suggested that, if the development of the framework gradually improved stakeholders' capacity, rather than seeking a radical reshaping, the communication could be improved as building trust between stakeholders could lead to successful NQF consensus (Coles \& Oates, 2004).

In the past few years, Japan has seen a rapid rise in foreign workers, with an average $18 \%$ increase year on year (Ministry of Health, Labour and Welfare, 2018). As 37.2\% of Japanese companies employ foreign experts, 6.7\% are planning to employ, and $5.1 \%$ used to employ, this indicates that importing highly skilled experts from overseas is becoming more important to Japanese companies (Nakahara, 2017). However, even though many foreign college students are eager to gain a position in Japan, few students are getting jobs (JASSO, 2018). Further, many foreign experts do not stay with a company for long. primarily because of the negative Japanese working environment (Ministry of Economy, Trade and Industry, 2017). To encourage foreign experts to stay longer in Japan, the needs to be a transparent, coherent, reliable, flexible, and relevant qualifications framework and system, so that foreign experts' skills can be properly assessed (Iwata, 2014). As the MHLW qualifications framework in Japan primarily targets vocational skills, the aim is only to assess expert's vocational skills rather than educate experts; therefore, at present, it is not linked to the Japanese education framework and system. As Japanese industries have poor internal education and training systems, links to the external education system are important (Tsukahara \& Hamana, 2017). However, from a survey of Japanese companies, $83 \%$ of the companies that used external training programs only used short term private education and training programs rather than higher education programs because they were "not familiar with higher institution programs" and "college programs were not practical" (Innovation Design \& Technology, 2016). However, another research has found that Japanese executives believe that academic degrees do have international labor applicability (Hamanaka, 2015). To enhance the vocational education college programs, the Ministry of Education, Culture, Sports, Science and Technology (MEXT) has been discussing a new framework for the development of new higher education focused on vocational education for highly professional experts by 2019 in which a strong relationship with industry is expected. However, the fuzzy definition of "highly professional" in the framework (Kaneko, 2017) could district industry interest and commitment.

To develop high-quality vocational education programs, an NQF could be a good instrument to develop the 
relationship between further education and industry (Iwata, 2012). However, discussions regarding such an NQF has not yet started in Japan, primarily because of political problems and bureaucratic issues as a successful NQF would require collaboration between several Government departments, which means that the responsibility for an NQF could cause tensions and unsuccessful discussions. Therefore, the ministries responsible for education and labor would need to have a strong motivation (Tuck, 2007), to share their opinions and reach a consensus in Japanese Government regarding a Japanese qualifications framework and system.

The goal of this research therefore is to explore the directions for a Japanese Qualifications Framework (JQF) by identifying the views of Japanese Government officials on the necessary Japanese qualifications for experts. If Japanese Government stakeholders believe that it is necessary to develop a JQF, then discussions should be forthcoming.

With respect to this aim, the following research questions were addressed. From the Japanese Government's point of view, (1) what factors need to be emphasized to assure an expert's quality?, (2) is there a conflict between Japan and other countries regarding expert's qualifications?, and (3) what factors are causing the conflicts?

\section{Method}

\subsection{Research Design}

This study used a qualitative case study design involving interviews. According to Sutton (2015) claimed that qualitative case studies involving interviews required a research design that could access the thoughts and feelings of the participants to understand the meanings that people ascribe to their experiences. Therefore, a semi-structured interview technique was applied to gain more detailed and clear understanding (Cohen, Manion \& Morrison, 2000; Terashita, 2011) of the thoughts of government officials regarding experts' qualifications, in which the terminologies may have several diverse meanings. To design the interview form, two experts in qualitative research and experts' qualifications were consulted and the necessary adjustments were made on the basis of the feedback obtained. To determine the study group, a purposeful sampling method was employed.

\subsection{Participants}

The study group for this research study was composed of 15 government officials working as directors at the Japan International Cooperation Agency (JICA). JICA is a government agency that coordinates official development assistance for the Japanese government, to assist in the economic and social growth of developing countries and to promote international cooperation. JICA provides bilateral aid as Technical Cooperation, which requires the employment for each program. When selecting experts, intensive discussions are held to reach an agreement with the counterpart country on the quality of the needed personnel. Through these experiences, the survey participants had significant knowledge and 10 to 15 years of experience regarding the necessary expert qualifications and more than five years as heads of expert selection committees. Participants gave informed consent and their identities were kept confidential.

\subsection{Limitations}

As data were collected from only one government institution, JICA, the results may not reflect the thoughts of the government. To check the robustness of the findings, on the basis of the findings, a follow-up survey targeting other government institutions is planned for the near future.

\section{Data Collection}

60-90 minutes semi-structured interviews were conducted. The effective interviewer was knowledgeable about the subject matter, an expert in interactions and communication (Cohen, Manion \& Morrison, 2000), and knowledgeable about the issues related to technical cooperation. All answers were recorded using a voice-recording device. Using a semi-structured interview structure allowed the participants to provide more detailed information on the topic as the interviewer could ask further questions outside the scope the predefined questions to clarify the respondents' meanings (Creswell, 2012).

\subsection{Interview Questions}

Two questions were prepared regarding the experts' qualifications, with three further questions asked to clarify the answers and obtain richer data. Interviewer interruptions during responses were avoided.

Q1. Have there been any conflicts between Japan and a counterpart country happen regarding the quality of the experts dispatched?

Do you feel that there is a gap between Japan and the counterpart countries in terms of the expert qualifications? 
If the answer to the first question was "No", the following question was asked to encourage the respondents to give depth to their answers.

Q1.1. Does "No" mean that either you have never discussed or negotiated the quality of the expert, or does this mean that your discussions and negotiations with a counterpart country resulted in a last resolution?

Q2. From your experiences on dispatching experts, please give your thoughts as to what factors affect a smooth agreement on the qualifications with a recipient country?

Additionally, detailed definitions and meanings for each answered factor were sought.

Q3. Do you think the factors are important, unimportant, or both when reviewing an expert's capabilities from the perspective of the Japanese Government? Please give me the reasons for your thoughts.

\section{Data Analysis}

The interviews recorded with the officials' permission using the voice-recording device were decoded and then the converted into digital text format, which was then evaluated using a content analysis to expose the facts within the data. Then themes and topics were identified, and codes were applied to the as part of the interpretation and description of the findings (Terashita, 2011). KH Coder was used to analyze the text content. Knowledge from the coded messages included in the interview protocols was acquired by processing the text, analyzing it, and visualizing the results (Higuchi, 2016). To map the words for the emerging themes and topics, a co-occurrence network analysis was applied, which drew a network diagram to highlight the words that had similar appearance patterns. KH Coder uses the Jaccard distance to measure the co-occurrence of term pairs, with frequently co-occurring terms being connected by lines in the visualization. The relative frequency of the terms was illustrated by the node size, and the relative frequency of the co-occurrence terms was illustrated by the thickness of the line connecting the respective nodes.

To increase the validity of the study, a triangulation method was applied; two researchers other than the interviewer who were familiar with expert dispatch reviewed the validity of determined themes, topics, and codes made necessary adjustments, and gave feedback.

\section{Findings}

\subsection{Conflicts between Japan and the Recipient Country}

In response to the question regarding existing conflicts on the dispatch of experts from Japan to a recipient country, one officer claimed that there were no conflicts, and 13 claimed that discussions and negotiations were often necessary to reach an agreement. Two officers said that there was a wide gap between the views of the two countries regarding qualifications of experts. Responses to this question indicated that there were conflicts and potential conflicts that required discussion and negotiation.

\subsection{Factors Affecting A Smooth Agreement with a Recipient Country Regarding Expert Quality}

The text from interview answers related to the question "From your experiences of dispatching experts, please provide your thoughts about which factors affect a smooth agreement on the qualifications with a recipient country?" were coded and categorized into similar meanings of words into categories and were labeled, the results were verified by two researchers, and adjustments were made. In this study, the labeled categories were called factors.

Figure 1. shows the 10 factors that affected a smooth agreement on expert quality with a recipient country. "Standardization" refers to the need to standardize the Japanese qualifications licensing framework or align the system to an international framework or system. "assurance of JICA on behalf of the Japanese Government (JICA/Government)" indicated a trustworthy quality assured expert selection by JICA on behalf of the Japanese government. "one-to-one negotiation" referred to intensive face-to-face discussions and negotiations with the recipient country.

The large percentages of factors related to licenses, academic degrees and work experience were identified as the key factors related to reaching an agreement on expert qualifications. 


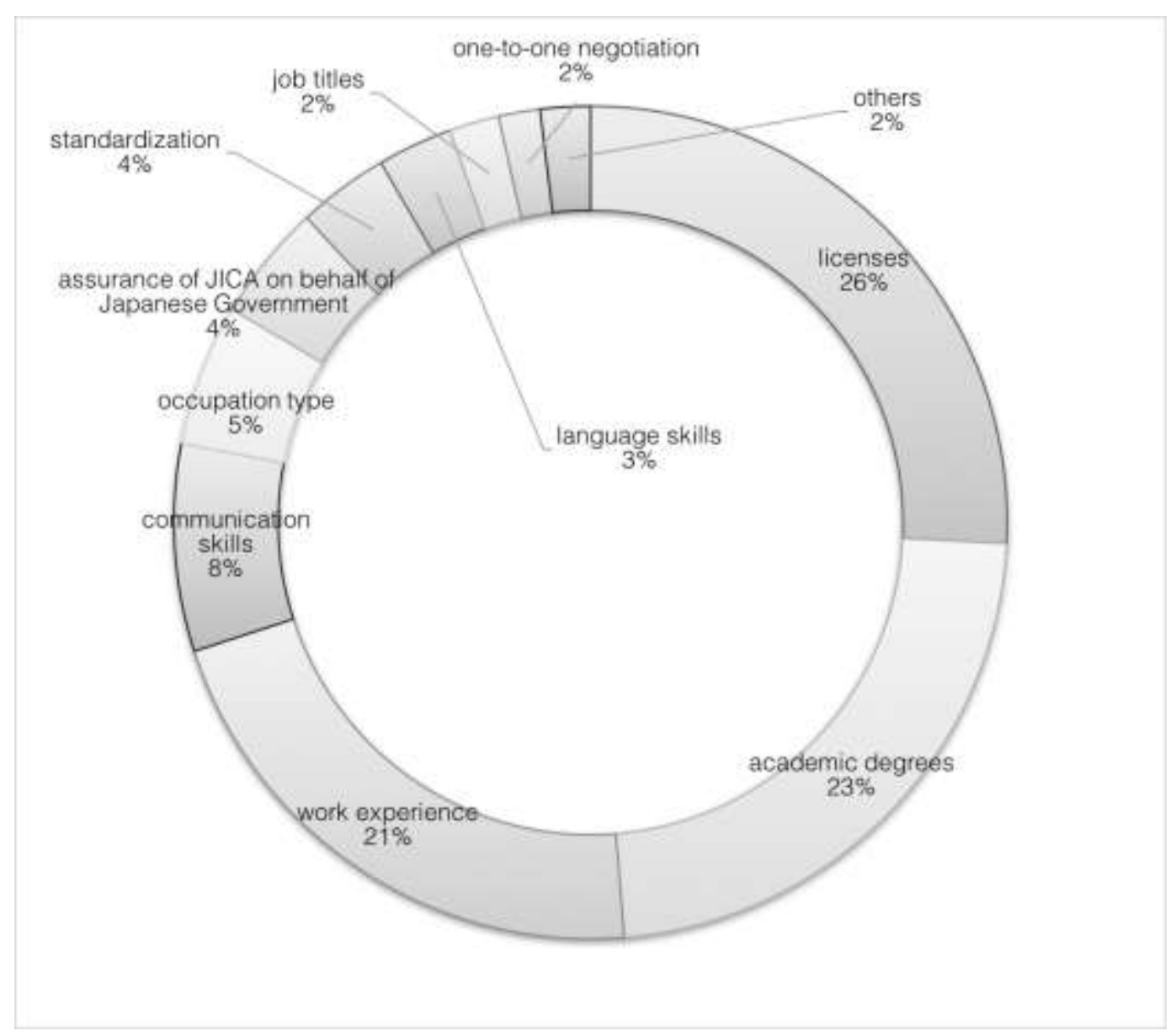

Figure 1. Factors related to the quality of experts

\subsection{Relationship among Factors}

To explore how the respondents perceived the nine factors, co-occurrence network analysis was employed to visualize the potential relationships between the terms. The text from the interviews for the factors that affected a smooth agreement on qualifications with a recipient country was used in the analysis. Frequently co-occurring terms in the visualization were connected by lines, the relative frequency of the terms was indicated by node size, and the relative frequency of co-occurrence of the terms was indicated by the thickness of the lines connecting the respective nodes.

The strongest connections to the word "expert" were "academic degrees," "occupation type" and "licenses", indicating that these were the most concerning factors when seeking agreement on selected experts with a recipient country (Figure 2).

Three clusters that had strong relationships were grouped under one theme, which revealed the views on the quality of the experts. The first of these clusters were "experts," "work experience," "occupation type," "JICA/Government," "license," "academic degrees," and "job titles"; the second of these clusters were "one-to-one negotiation" and "standardization"; and the third of these clusters were "communication skills" and "language skills" (Figure 2). 


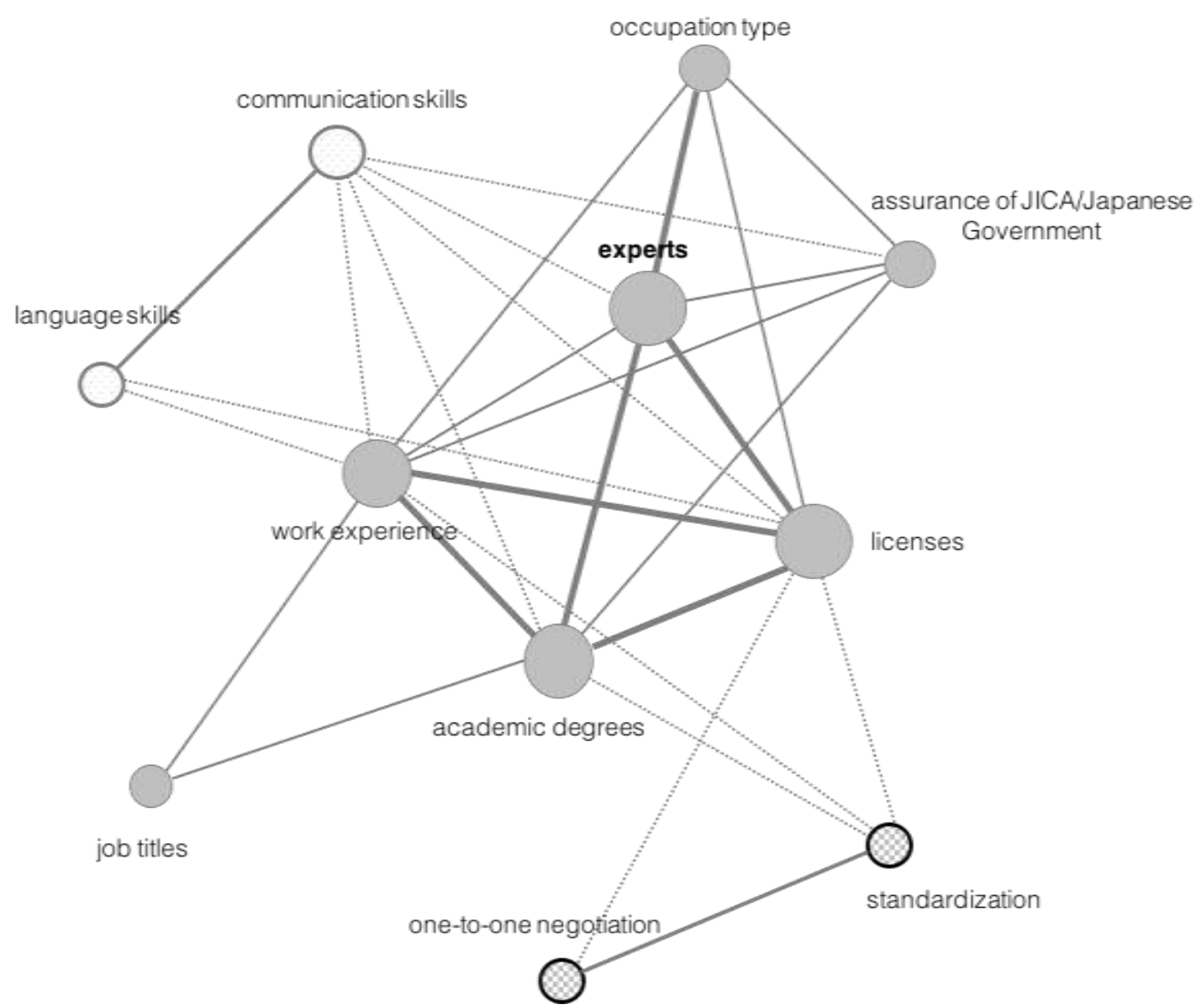

Figure 2. The KH Coder Co-occurrence Network regarding the quality of experts

\subsection{Importance of the Factors}

The responses to the question as to the importance of the 10 factors for Japan were sorted and counted into positive (important) and negative (unimportant) responses, the results of which were then reviewed by two researchers, and adjustments were made.

All respondents thought that work experience and occupation type were important factors when reviewing the capabilities of an expert (Figure 3), and standardization, communication skills and job position were not seen as important (Figure 3). Most respondents thought that one-to-one negotiations were important, and the responses academic degrees and licenses were mixed (Figure 3). 


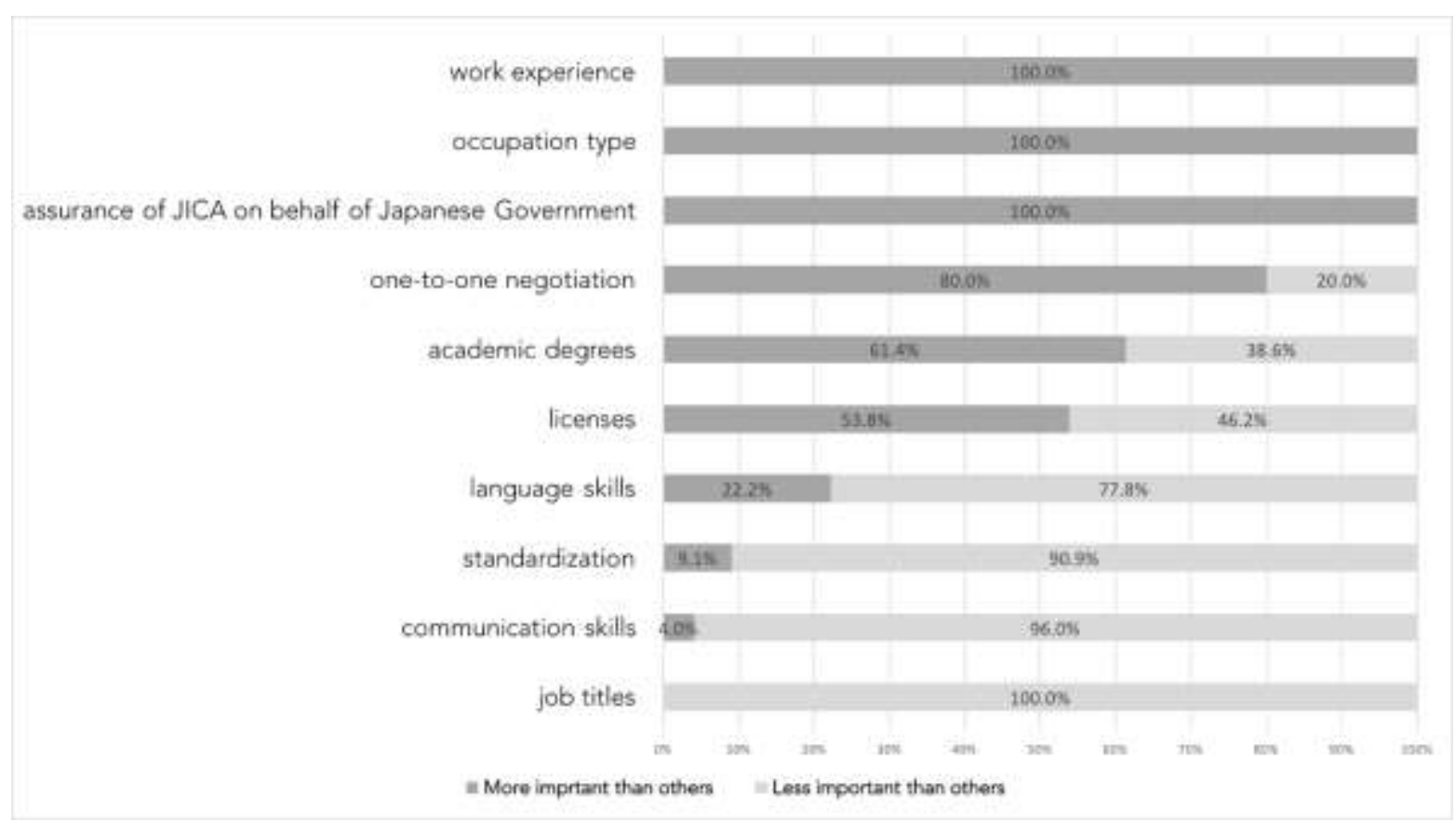

Figure 3. Factor priorities

5.5 Reasons for the Important Factors for Reviewing the Capabilities of An Expert from a Japanese Perspective.

Responses for the important factors for reviewing the capabilities of an expert reflected the views of the Japanese Government regarding JQF. Similar responses were combined, which were reviewed by two researchers and adjustments were made. 
5.5.1 Reasons Why the Factor was Important

Table 1 . Reasons why the factor is important

\begin{tabular}{|c|c|}
\hline Factor & Reasons \\
\hline \multirow{2}{*}{$\begin{array}{l}\text { Assurance of JICA on behalf of } \\
\text { Japanese Government } \\
\text { (JICA/Government) }\end{array}$} & $\begin{array}{l}\text { Most powerful factor whenever a qualification is not immediately } \\
\text { accepted }\end{array}$ \\
\hline & $\begin{array}{l}\text { Guarantee by a trustworthy institution, JICA, on behalf of the } \\
\text { trustworthy country, Japan. }\end{array}$ \\
\hline \multirow[t]{3}{*}{ Work experience } & Emphasized by many industries. \\
\hline & Practical experience is needed to be an expert after graduation. \\
\hline & To obtain practical skills that are useful in the field. \\
\hline \multirow[t]{2}{*}{ Occupation type } & To determine the necessary work experience in the field. \\
\hline & To determine the criteria to assess and select an expert. \\
\hline \multirow[t]{2}{*}{ One to one negotiation } & $\begin{array}{l}\text { To explain the efficacy of local Japanese qualifications when the } \\
\text { qualifications are not familiar to a recipient country. }\end{array}$ \\
\hline & $\begin{array}{l}\text { To build the mutual trust necessary between Japan and a recipient } \\
\text { country for a successful technical cooperation. }\end{array}$ \\
\hline \multirow[t]{5}{*}{ Academic degree } & $\begin{array}{l}\text { Indispensable to work in an international institution such as the United } \\
\text { Nations, the IMF and other development banks. }\end{array}$ \\
\hline & $\begin{array}{l}\text { Master's degree as a minimum qualification for an expert requested by } \\
\text { many recipient countries. }\end{array}$ \\
\hline & The most persuasive evidence for recipient countries. \\
\hline & $\begin{array}{l}\text { Ph.D. as a decisive qualification to become the head of an international } \\
\text { team (which most Japanese high skilled experts do not have it). }\end{array}$ \\
\hline & To strengthen the value of the local license. \\
\hline \multirow[t]{2}{*}{ License } & $\begin{array}{l}\text { To assess and present universal skills (such as skills in electrical } \\
\text { technology). }\end{array}$ \\
\hline & (international standardized license) directly linked to skills. \\
\hline Language skills & $\begin{array}{l}\text { To fit into new environments (comfortable daily life brings successful } \\
\text { outcomes). }\end{array}$ \\
\hline Standardization & $\begin{array}{l}\text { To improve the Japanese qualifications framework and system to be } \\
\text { able to properly transfer various overseas licenses to Japanese local } \\
\text { licenses. }\end{array}$ \\
\hline Communication skills & $\begin{array}{l}\text { To build up a mutual trust between Japanese experts and recipient } \\
\text { country staff for successful technical transfer. }\end{array}$ \\
\hline Job titles & (no response) \\
\hline
\end{tabular}

The reasons why the factors were considered important are shown in Table 1. All respondents claimed that, when any information regarding the quality of an expert was not seen as suitable, the response that "JICA is responsible for the selected expert" proved persuasive as JICA was trusted by the recipient countries because of the excellent outcomes 
from past technical cooperation.

The most frequent response as to why work experience was most important was because practical skills were considered the key assessment for experts. Most respondents (12) claimed that practical skills could only be obtained through good work experience.

Occupation type was recognized as a starting point for expert reviews (10 respondents). As occupation type was used to determine the necessary quantity and the quality of work experience, it was recognized as important information.

Several respondents (6) felt that building a mutual trust was the key to successful technical cooperation and that oneto-one negotiation was a good opportunity to build mutual trust.

Academic degrees were seen as indispensable for working internationally, with most (8) agreeing that a Master's degree was needed for executive experts. Two respondents felt that a Ph.D. was necessary for the head of an international technical cooperation team; however, most highly skilled Japanese experts did not have these qualifications. As academic degrees are persuasive international qualifications, some respondents (4) used this to strengthen the value of a Japanese local license; for example, an academic degree in international public health was seen to be related to a Japanese public health nursing license.

Licenses were seen as important qualifications as long as they were standardized licenses; however, it was recognized that these do not exist in Japan (8). Many respondents (7) insisted that Japanese qualifications should be standardized to deal with the increase in foreign experts with foreign licenses.

Although language skills and communication skills were seen as good to have but not a priority", it was seen that these two skills were collateral skills for success in the Expert Dispatch program (Language skills, three respondents; Communication skills, two respondents). 
5.5.2 Reasons Why the Factors were not Important

Table 2. Reasons why a factor was not considered important

\begin{tabular}{ll}
\hline Factor & Reasons \\
\hline $\begin{array}{l}\text { Assurance of JICA on behalf } \\
\text { of Japanese Government } \\
\text { (JICA/Government) }\end{array}$ & (no protocol) \\
Work experience & (no protocol) \\
(no protocol) & \\
Occupation type & Just a tool to explain qualifications. \\
One-to-one negotiation & Does not reflect the expert's skill quality. \\
Academic degree & Become useless licenses because most industries did not adopt them. \\
License & $\begin{array}{l}\text { Can be substituted with the reputation of the expert in the field. } \\
\text { (Japanese licenses) do not function internationally. } \\
\text { Time consuming to update the frequent changes to the licensing framework and } \\
\text { system. }\end{array}$
\end{tabular}

Language skills $\quad$ Even with low English skills, highly skilled experts are required.

Standardization Standardization disturbs the progress of skills.

(Japanese licenses) Standardization is not realistic.

Communication skills Just a tool to support smooth technical skills transfer.

Job titles (Japanese title) Limited usage; not a cross sectional qualifications, works only within the company

Not directly linked to the skill level. Additional information is needed to explain the value of the work experience.

(Japanese title) Determined by length of service and age rather than skill level.

Table 2 shows why certain factors were not deemed to be important by the respondents; there was no response regarding the JICA/Government, work experience, or occupation type.

For one-to-one negotiations, two respondents claimed that JICA should not rely on one-to-one negotiations but needs to focus on developing a competitive and transferable qualifications framework. It was believed, that to look beyond successful Dispatch Expert programs, Japanese experts needed to have more presentable qualifications.

Three respondents thought that academic degrees did not reflect the quality of an expert's skill based on the fact that many excellent Japanese experts do not have presentable degrees.

Nine respondents claimed that Japanese licenses did not function internationally because they were neither comparable nor transferable to other country's licenses. Three respondents thought that, although Japan has many types of licenses, these were not usable because most industries did not adopt them, and they also insisted that licenses should meet the demands in the industry. Five respondents were also concerned about the frequent changes 
in the licensing framework and claimed that a license had limited effectiveness in JICA and that updating the changes was time consuming.

For language skills, 13 respondents felt that, as the aim of technical cooperation was skills transfer, only minimal English speaking skills were necessary.

Ten respondents did not think that standardizing the licensing framework was practical for Japan, claiming that the licensing system was complicated as many stakeholders needed to be involved to improve it; therefore, they had given up hoping for licenses that could be used internationally. Three respondents believed that, as skills should be developed in line with industrial expansion, a qualifications system should not be stuck with a robust framework and claimed that standardization hindered framework flexibility.

Although communication skills were seen to be support tool for successful technical skills transfer, while technical skills were seen to be the core (11 respondents).

Three respondents claimed that Japanese job titles had limited use as they were not cross-sectional qualifications and generally only referred to positions within a specific company. Eleven respondents claimed that, as a Japanese job titles were related to length of service and age rather than skill level, there were not useful.

5.5.3 Challenges regarding the Qualifications of Experts

Table 3. Challenges regarding the qualifications of experts

\begin{tabular}{ll}
\hline Factor & Reasons \\
\hline Work experience & Do not understand about the value of work experience in unfamiliar fields. \\
& No effective qualifications better than a work experience. \\
& Worthless of a work experience in the new field because of an authoritarian recipient countries.
\end{tabular}

Occupation type Updating frequent changes to occupation categories take time.

Academic degree Getting an academic degree while working is difficult in Japan.

Weak competitiveness of Japanese experts; most Japanese executive experts have only a bachelor's degree, while most recipient country's executive experts have master's or doctoral degrees.

License Japanese government policy welcoming foreign experts will force Japan to develop a local license framework aligned with the international framework which will be challenging.

Standardization International qualifications frameworks that are widely used overseas could make JICA's flexible negotiation strategies unworkable; however, standardizing Japanese qualifications frameworks to be aligned with the international framework would takes a long time.

Most licenses do not align with international frameworks. It takes too long time to align all these qualifications to the international frameworks.

Thirteen respondents highlighted the insufficiencies in Japanese qualifications, claiming that the only way to promote the quality of an expert was from their work experience; that is, Japanese qualifications were not seen to be effective as evidence of an expert's skills. However, they also realized that a work experience alone was not enough. Three respondents claimed that they had trouble finding adequate information in new fields when a recipient country had asked them to replace the work experience information in a new field with information from a more familiar field. Recipient countries were regarded as authoritarian.

Two of the most concerning factors were academic degrees and standardization (11 respondents each) claiming that it was difficult to get an academic degree while working. In Japan, as an academic degree is not linked to promotion, it does not have great value. As gaining academic degrees while working is very difficult, unlike experts from other countries, many Japanese executive experts do not have presentable academic degrees.

Respondents did wonder that, if international qualifications frameworks are becoming more widely used in many countries, would a framework become mandatory for the assessment and review of Japanese experts and would a 
recipient country accepts the selected Japanese experts if they did not have presentable qualifications? However, most respondents felt that improving a Japanese qualifications framework to become aligned to an international framework would take a long time and that any mandatory requirements to use international qualifications frameworks would deeply affect the success of the Dispatch of Experts program; this concern was also expressed for licenses (6 respondents).

Two respondents mentioned about occupation type; as this is closely related to an expert's field, JICA determines the criteria when reviewing experts by an occupation type. Further as there are frequent changes in the categorization of occupation because of labor market needs, respondents were concerned that JICA would have to constantly update and improve the criteria for every change.

\section{Discussion and Conclusion}

\subsection{Factors to Assure the Quality of an Expert}

From the combined results of the co-occurrence network analysis, the factors to ensure the quality of an expert were sorted into four categories: basic, core, supplementary, and safety net.

Occupation type was categorized as a basic factor. As the required capabilities were determined based on occupation type, the required qualifications were also based on occupation type.

Work experience, academic degrees and licenses were categorized as core factors. Work experience was the most usable and important factor from a Japanese perspective; however, from the perspective of other countries, academic degrees and licenses were also important factors that many Japanese experts did not have.

Job titles and language skills, and communication skills were categorized as supplementary factors. Job titles were only used to enhance the value of work experience and language skills and communication skills helped an expert to move a project forward; therefore, although these factors were not considered core for experts, they were considered necessary.

Assurance by JICA on behalf of the Japanese Government was categorized as the safety net. This means that, when a selected expert with basic, core, and supplementary information was not accepted by a recipient country, the phrase "JICA is responsible for the expert" was used as a trump card that works effectively at the last minute.

\subsection{Conflicts between Japan and other countries regarding qualifications in experts.}

Most officers expressed the view that there was a conflict between Japan and other countries. The co-occurrence network analysis found that "academic degrees" and "licenses" were strongly connected to the idea of "experts," which reflected the respondents' concerns that Japan had potential problems regarding academic degrees and licenses.

It is difficult to gain academic degrees, while working in Japan as there is little interaction between higher education and industry. Although academic degrees are the only It comes from little interactive relationships between higher education and industry. Although academic degree are the only transparent and internationally workable qualifications in the current Japanese framework, most Japanese experts do not have presentable academic degrees. Respondents claimed that they struggle because many Japanese experts had only a bachelor's degree, whereas other countries' experts had master's or doctoral degrees. Most respondents expressed deep concern about this situation as they felt it would result in Japanese experts having weak international competitiveness.

The respondents had two opposing views on licenses. Some were concerned about the localized Japanese licenses as they did not align with international frameworks, so were basically useless internationally. Others thought that the Japanese licensing system should be standardized align with the international framework to deal with the increase in foreign experts working in Japan and others expressed concern that, if the international licensing framework became mandatory in Japan, this would adversely affect the Dispatch of Experts program. However, they also felt that the current licenses were becoming dead licenses as they were not readily accepted by most industries and that improving complicated Japanese licensing frameworks to align it to international frameworks would be needlessly time consuming. they also expressed concern that any mandatory use of an international standardized framework would make JICA's current flexible negotiation strategies unworkable as the safety net of "assurance of JICA on behalf of Japanese Government" would no longer work.

The two biggest issues of academic degrees and licenses were seriously recognized by respondents, with all realizing that work experience alone was not sufficient information when presenting an expert's capabilities to a recipient country. Therefore, many officers felt that it was necessary for Japan to develop a qualifications framework that could function both domestically and internationally as the current Japanese qualifications framework and system did 
not function either.

To solve these issues, vertical as well as horizontal progression in the Japanese qualifications system is necessary. Vertical progression refers to the development of pathways to a higher level of skills. In Japan, there are few qualifications that are designed to develop the skills of executive experts, which means that currently few experts have presentable qualifications. As many of the government officers believed that the best and most persuasive qualifications for experts were academic degrees, such as master's and doctoral degrees, the highest priority should be placed on improving the higher education system so that the academic degrees reflected the expert's skills.

Horizontal progression refers to the development of qualifications to broaden pathways so that Japanese domestic qualifications can be aligned with internationally recognized qualifications. To broaden the qualifications, the Japanese framework and system needs to be aligned with recognized international qualifications frameworks. Because of the increase in cross border higher education programs, the Japanese higher education system is becoming more transferable; however, the Japanese licensing system remains domestic and is not transferable. As the Japanese domestic licensing framework and system involves too many stakeholders; it could take a long time to develop a framework and system; therefore, most the JICA officers thought that the licensing framework and system reform would be more difficult rather than higher education framework and system. Therefore, higher education should take the initiative to improve JQF.

To build vertical pathways from the world of work to higher education, a common language for levels, awards, types, outcomes and credits is needed ensure that the expert learning system, its component parts, and the relationships are transparent and easy to understand. There also needs to be a mechanism that brings together the different providers, users and other stakeholders from education and industry to identify mutual interests and coordinate their activities. Raffe (2013) claimed that such a mechanism could enable standards to be easily updated and made more relevant and the learning system to become more coherent and demand-driven.

To build horizontal pathways that span the domestic labor market and the international market, education requires both common language and a framework that would make the qualifications more transparent, and thereby making it easier to improve standards, and to relate qualifications to both domestic and international markets.

The findings from this research indicate that JQF would be the best approach to developing these pathways, as it could function as a common language for stakeholder engagement and coordination, and transparency as has been proven in many countries in which NQFs have been implemented (Raffe, 2013).

Young $(2007,2008)$ claimed that, if there is no actual embeddedness to connect education or work, the demand for any qualifications would be low to non-exist. In addition, Cort (2010) also noted that NQF should be seen as a policy driven tool. This research explored the perceptions of Japanese Government officers working at an expert exchange who understood the current situation in Japan and were able to represent the Japanese Government's view. It was found that they believed that there was an insufficient qualifications framework and system in Japan compared to other countries. Therefore, it could be concluded that the Japanese Government understands the situation. Japan should enter in serious discussions about the establishment of a JQF with stakeholders in education, industry, and government, as high-quality higher education programs are needed for experts that Japanese experts are both domestically and internationally competitive.

\section{References}

Allais, S. (2010). The implementation and impact of National Qualifications Frameworks: Report of a study in 16 countries. ILO. Geneva.

Artess, J., Hooley, T., \& Mellors-Bourne, M. (2017). Employability: A review of the literature 2012 to 2016. Higher Educaiton Academy. York, United Kingdom.

Bateman, A., \& Coles, M. (2013). Qualifications frmameworks and quality assurance of education and training. Prepared for the World Bank. Mike Coles Ltd.

Cedefop. (2010). Changing qualifications: A review of qualifications policies and practices. Cedefop Reference series, 84.

Cedefop. (2013). The role of qualifications in governing occupations and professions. Working Paper, 20.

Cedefop. (2015). National Qualifications Framework Development in Europe. Luxcenburg, EU.

Cohen, L., Manion, L., \& Morrison, K. (2000). Research Methods in Education. London. England: Routledge. https://doi.org/10.4324/9780203224342 
Coles, M., \& Oates, T. (2004). European reference levels for education and training: promoting credit transfer and mutual trust. Cedefop Panorama Series, 109. Luzemburg.

Creswell, J.W. (2012). Educational Research Planning, Conducting and Evaluating Quantitative and Qualitative Research. ( $2^{\text {nd }}$ ed.). Newjersey: Pearson.

Cort, P. (2010). Stating the Obvious: the European Qualifications Frameworks is not a neutral evidence-based policy tool. European Educational Research Journal, 9(3), 304-316. https://doi.org/10.2304/eerj.2010.9.3.304

European Training Foundation. (2013). Global National Qualifications Framework Inventory. Torino, Italy.

European Commission. (2008). The European Qualifications Framework for Lifelong Learning (EQF). Luxembourg.

Hamanaka, J. (2015). Barrier against Higher Education Innovation. Higher Education Research, 18, 69-87.

Higuchi, K. (2016). A Two-Step Apporach to Quantitative Content Analysys: Tutorial Using Anne of Green Gables (Part 1), Ritsumeikan Social Sciences Review, 53(3), 77-91.

Innovation Design \& Technology. (2016). Survey on Lifelong Learning for adults. Research Report for MEXT Innovation Project.

Iwata, K. (2012). EU- QF and EQF. Study of Qualifications Framework, 102, 163-188.

Iwata, K. (2014). Towards the early construction of Japanese Qualifications Framework: JQF is the key nod for addressing many challenges of human resources development in Japan. Journal of Polytechnic, 30(1), 135-143.

JASSO. (2018). Foreign Students Survey: Career survey on foreign students in Japan. Japan Student Services Organization.

Kaneko, M. (2017). Meaning of "Professional College". Japanese Journal of Labour Research, 287, 4-13

Ministry of Economy, Trade and Industry. (2017). Securing experts and creating innovations, 2016 White Paper on International Economy and Trade, 2(1), 157-178

Ministry of Health, Labour and Welfare. (2018). Conditions for foreigners working in Japan. Jhttp://www.mhlw.go.jp/file/04-Houdouhappyou-11655000-Shokugyouanteikyokuhakenyukiroudoutaisakubu-G aikokujinkoyoutaisakuka/1496p75g.pdf

Misko, J. (2012). The role of qualifications in foregin labour mobility in Australia. Reasearch Report. National Centre for Vocational Education Research.

Nakahara, H. (2017). The Innovation Activities by the Utilization of the Foreign Talented Person. Chiba Univ. Journal of Ecnomic Research, 31(3/4), 345-473

Organisation for Economic Co-operation and Development. (2010). Learning for Jobs. Synthesi. Report of the OECD Reviews of Vocational Education and Training.

Oliver, D., \& Walpole, K. (2017). How are links between a Naitonal Qualifications Framework, job roles and pay mediated by industrial relations insitutions in manufacturing?. Journal of Vocational Education \& Training, 69(4), 576-595. https://doi.org/10.1080/13636820.2017.1326162.

Raffe, D. (2013). What is the evidence for the impact of National Qualifications Frameworks? Comparative Education, 49(2), 143-162. https://doi.org/10.1080/03050068.2012.686260

Sutton, J., \& Asutin, Z. (2015). Qualitative Research: Data Colletction, Analysis, and Management. The Canadian Journal of Hospital Pharmacy, 68(3), 226-231. http://dx.doi.org/10.4212/cjhp.v68i3.1456

Terashita, T. (2011). Qualitative Rersearch Method. Japanese Radiological Phisycs and Technology, 67(4), 413-417. https://doi.org/10.6009/jjrt.67.413

Tsukahara, S., \& Hamana, A. (2017). Lifelong Learning and College Education. Journal of Labour Policy and Training, 687, 27-36.

Tuck, R. (2007). An Introductory Guide to National Qualifiactions Framework: Conceptual and Practical Issues for Policy Maker. ILO. Geneva, Switzerland.

Young, M. (2007). Qualifications Frameworks: some conceptual issues. Education, 42(4), 445-457. https://doi.org/10.1111/j.1465-3435.2007.00323.x

Young, M. (2008) Towards a European qualifications framework: some cautionary observations. Journal of European Industrial Training, 32(2/3), 23-41. https://doi.org/10.1108/03090590810861677 